\title{
Application of the protection motivation theory for predicting COVID-19 preventive behaviors in Hormozgan, Iran: a cross- sectional study
}

Roghayeh Ezati Rad', Shokrollah Mohseni², Hesamaddin Kamalzadeh Takhti ${ }^{3}$, Mehdi Hassani Azad ${ }^{4}$, Nahid Shahabi ${ }^{1}$, Teamur Aghamolaei ${ }^{5^{*}}$ (i) and Fatemeh Norozian ${ }^{2}$

\begin{abstract}
Background: The high prevalence and mortality of coronavirus disease 2019 (COVID-19) have made it the most important health and social challenge around the world. However, this disease can be largely prevented by adherence to hygienic principles and protective behaviors. It seems that identifying the processes involved in protective health behaviors can be effective in planning and implementing suitable interventions to encourage the community toward protective behaviors. Therefore, the present study aimed to predict the preventive behaviors of COVID-19 according to the Protection Motivation Theory (PMT).

Methods: This cross-sectional study was conducted over 2 months in Hormozgan Province, Iran. The study population consisted of all citizens above the age of 15 years. An online questionnaire was used to collect the data. The questionnaire link was available to the participants through social networks. The questionnaire consisted of two sections, including the demographic information and the PMT constructs. All statistical calculations and hypothesis testing were performed in SPSS Version 21 and AMOS Version 21. The significance level was considered to be 0.05 for hypothesis testing.

Results: A total of 2032 subjects, with the mean age of $34.84 \pm 9.8$ years $(r=15-98)$, participated in this study. Most of the participants were $31-40$ years old, female (60.4\%), married (72\%), urban residents (87.3\%), and employed (58.8\%). The majority of them also had a bachelor's degree or higher (58.8\%). Significant positive correlations were observed between the preventive behaviors of COVID-19 and the perceived vulnerability $(r=0.192, P<0.001)$, perceived severity $(r=0.092, P<0.001)$, response efficacy $(r=0.398, P<0.001)$, self-efficacy $(r=0.497, P<0.001)$, and protection motivation $(r=0.595, P<0.001)$. On the other hand, significant negative correlations were found between the preventive behaviors of COVID-19 and maladaptive behavior rewards $(r=-0.243, P<0.001)$ and perceived costs $(r=-0.121, P<0.001)$.

(Continued on next page)
\end{abstract}

* Correspondence: teaghamolaei@gmail.com

${ }^{5}$ Cardiovascular Research Center, Hormozgan University of Medical Sciences, Bandar Abbas, Iran

Full list of author information is available at the end of the article

(c) The Author(s). 2021 Open Access This article is licensed under a Creative Commons Attribution 4.0 International License, which permits use, sharing, adaptation, distribution and reproduction in any medium or format, as long as you give appropriate credit to the original author(s) and the source, provide a link to the Creative Commons licence, and indicate if changes were made. The images or other third party material in this article are included in the article's Creative Commons licence, unless indicated otherwise in a credit line to the material. If material is not included in the article's Creative Commons licence and your intended use is not permitted by statutory regulation or exceeds the permitted use, you will need to obtain permission directly from the copyright holder. To view a copy of this licence, visit http://creativecommons.org/licenses/by/4.0/. The Creative Commons Public Domain Dedication waiver (http://creativecommons.org/publicdomain/zero/1.0/) applies to the data made available in this article, unless otherwise stated in a credit line to the data. 
(Continued from previous page)

Conclusion: The present findings showed that maladaptive behavior reward and fear negatively predicted the protective behaviors. On the other hand, response efficacy and self-efficacy positively predicted the protective behaviors; the impact of self-efficacy was the strongest. Overall, the information provided in this study can contribute to health policymaking in Iran.

Keywords: Protection motivation theory, Behavior, COVID-19, Iran

\section{Background}

Coronavirus disease 2019 (COVID-19), which was first detected in Wuhan, China, in December 2019, is a new respiratory disease, caused by a newly discovered coronavirus [1]. The World Health Organization (WHO) introduced COVID-19 as an international public health emergency on January 30, 2020 [2] and declared it as a pandemic on March 11, 2020 [3]. This disease has both short- and long-term impacts on communities, health systems, and individuals [4]. The uncertainties surrounding the nature of this global pandemic, social restrictions, preventive measures, and lockdown have caused physical and mental problems for individuals [5].

In addition to quarantine policies, social distancing [6, 7] and personal hygiene are considered essential by the WHO to combat COVID-19. Some preventive measures include social distancing (at least a one-meter distance), use of face masks, covering the face with a tissue paper or cloth while coughing or sneezing, washing the hands regularly, and not touching the mouth, nose, or eyes. Besides, stress and anxiety management can help prevent this disease $[6,8,9]$. In addition to these individual measures, it is important to take other protective measures into account, such as occupational health, employees' physical health, proper ventilation in closed environments, and access to valid health information to control the disease $[1,10]$.

The hot weather of the summer, the impossibility of proper ventilation during this season, and social gatherings in closed environments led to the increased prevalence of COVID-19 during summer. Besides, high humidity made it difficult for people to use face masks outdoors during summer. In Iran, the cultural background of people, who are known to be hospitable, was also influential in the increased prevalence of this disease. Generally, hospitality is more prominent in southern provinces of Iran, especially in Hormozgan Province [11]. Also, close family and social relationships in this province could affect collective activities and norms during the COVID-19 epidemic [12, 13]. It should be noted that the religious beliefs of Iranians and Hormozgan residents may influence stress management and mental relaxation $[14,15]$.

COVID-19 is a highly contagious disease, which can rapidly spread and infect many people. The adverse outcomes of this disease are severe and associated with acute respiratory problems and mortality. However, no definitive treatment or vaccine has been developed for this disease so far; therefore, protective measures seem to be essential $[8,16]$. Generally, healthy behavior theories can help us identify the factors involved in protective behaviors to plan health promotion programs. The Protection Motivation Theory (PMT), which was first introduced by Rogers in 1975, has been widely used as a framework to predict protective behaviors [17, 18]. PMT assumes that adopting a protective behavior against health threats is dependent on personal motivation for self-protection.

In PMT, fear is appraised to predict and encourage protective behaviors and explain the cognitive processes involved in threat and coping appraisals [18]. Threat and coping appraisals can lead to adaptive or maladaptive responses, which are considered as threats to one's health [19]. In PMT, threat appraisal depends on the following factors: (1) one's belief in the severity of the problem (perceived severity); (2) one's estimation of the chance of being affected by the disease (perceived vulnerability); and (3) one's belief in the positive aspects of unhealthy behaviors (perceived rewards). Therefore, if the perceived severity and vulnerability are high, and the perceived rewards are low, there is a stronger motivation for engagement in health-promoting behaviors.

In PMT, coping appraisal involves: (1) one's evaluation of the efficacy of the protective behavior in coping with the threat (response efficacy); (2) one's belief in one's own capability of managing protective behaviors (self-efficacy); and (3) one's estimation of costs (including money, time, and energy) and efforts to perform protective behaviors (perceived response cost). Overall, the response efficacy and self-efficacy are expected to reinforce coping appraisal, while the response cost is expected to reduce it (Fig. 1) [20].

Generally, fear is a mediator between perceived vulnerability, perceived severity, and threat appraisal. Therefore, if one feels vulnerable to a serious health threat, the level of fear is increased, and one is further motivated to adopt a preventive/protective behavior. During global pandemics, such as the COVID-19 pandemic, people experience fear and anxiety and realize that there is no definitive treatment for the disease. Also, fear of 


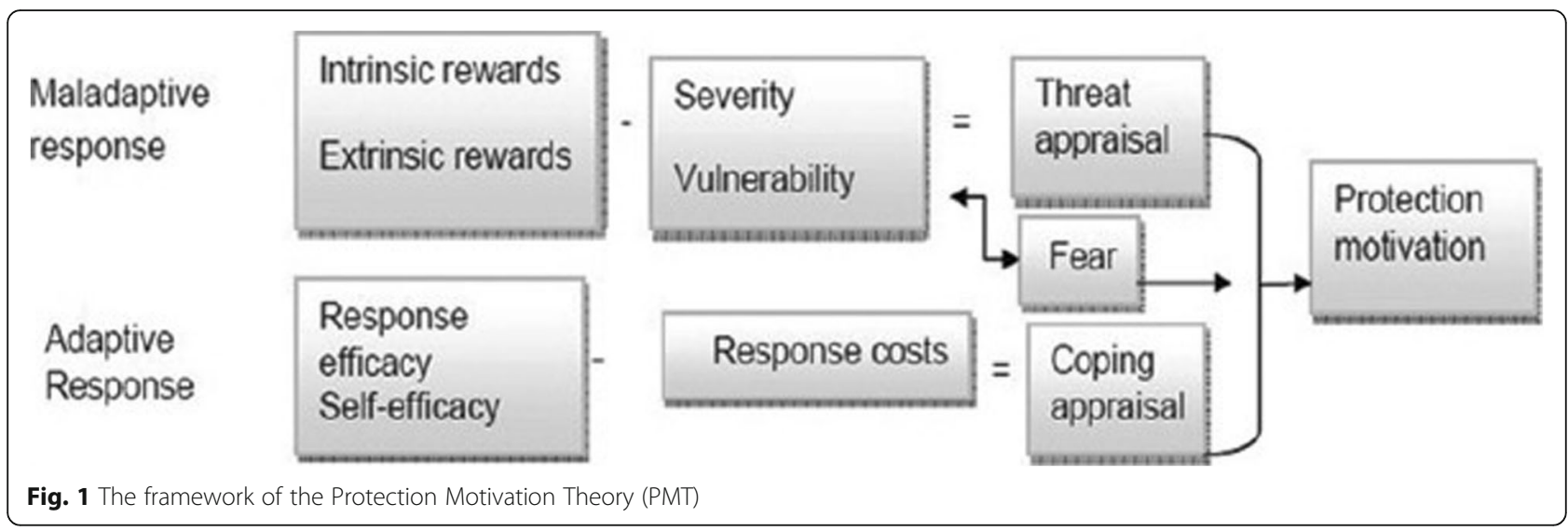

increased patient morbidity and mortality has raised public concerns and led to public panic, stress, and mental health problems [21, 22].

Coping and threat appraisal processes are integrated to develop protection motivation [23]. The literature suggests that PMT can accurately predict the adoption or non-adoption of protective behaviors [24-26]. So far, PMT has been used to investigate different behaviors, such as administration of influenza vaccine [27], preventive behaviors during the H1N1 pandemic [24], cancer preventive and sun-protection behaviors [28, 29], SARS preventive behaviors [30], and preventive behaviors for infectious diseases and skin cancer [31-33].

Iran is located in West Asia, and Hormozgan Province is located in south of Iran on the Persian Gulf coastline. This province consists of 13 counties, and its population is estimated at $177,641,500$ according to the census in 2017 [34-36]. Since no definitive treatment or vaccine has been discovered for COVID-19, adopting protective behaviors is the best way to control this disease. Therefore, understanding the adaptive and maladaptive responses can help us identify the causes of people's reluctance to use protective behaviors and the ways to address these issues. Therefore, this study was conducted to predict the protective behaviors of COVID-19, based on the PMT in the population of Hormozgan Province, Iran.

\section{Methods}

\section{Study design}

This cross-sectional study was conducted over 2 months (from March 2020 to April 2020) in Hormozgan Province, Iran. The questionnaire was available in the online Google Docs platform. The target population consisted of Hormozgan Province residents, aged above 15 years.

This research was approved by the Ethics Committee of Hormozgan University of Medical Sciences (ID No.: 980470, Ethics Code: IR.HUMS.REC.1398.479). The participants completed the questionnaires voluntarily, and their voluntary participation was appreciated on the first page of the questionnaire.

\section{Sampling method}

Considering the risk of COVID-19 transmission through paper questionnaires, the data were collected online, using different messaging platforms (e.g., WhatsApp and Telegram channels of the research centers, School of Health, and Hormozgan University of Medical Sciences). The link to the questionnaire was sent in different online groups. The samples that received the link were asked to complete the questionnaire and send it to other people they know. Also, with the cooperation of health centers, the questionnaire link was sent to all individuals who were covered by the health centers in villages and cities. Besides, the link was sent to ten online information groups related to COVID-19 through the university's public relations network.

In this study, considering the data collection method, there was no limitation in the number of samples. Also, completing the questionnaires was completely voluntary. On the first page of the questionnaire, after explaining the objectives of the study, the participants were asked to sign a consent form. The inclusion criteria were the minimum age of 15 years, literacy, and residence in Hormozgan Province. On the other hand, the exclusion criterion was unwillingness to participate in the study.

\section{Data collection}

The data collection instrument was a researcher-made questionnaire. The validity of this questionnaire was assessed by the content validity method. The content of the questionnaire was extracted from credible sources, including relevant books and academic papers. It was also approved by a panel of three experts (health education and promotion specialists) after the necessary changes were made both qualitatively and quantitatively. The experts were asked to rate the items in terms of the words chosen, the order of presentation, and scoring. 
According to their feedback, revisions were made in the questionnaire. Its reliability was approved, based on the Cronbach's alpha method. The questionnaire consisted of two parts. The first part included the demographic information, such as age, gender, marital status, education, occupation, background diseases, and history of smoking tobacco. The second part was related to the PMT constructs. All constructs of PMT, except for behavior, were rated on a five-point Likert scale (range: 1-5), ranging from "strongly agree" to "strongly disagree". Also, the behavior construct was rated on a five-point scale (range: 0-4), ranging from "never" to "always".

The perceived vulnerability (e.g., "I may also get infected with COVID-19.") was tested in four items, with the scores ranging from 4 to 20 . The perceived severity (e.g., "There is a chance of early death in the event of infection with COVID-19.") was tested in six items, with the scores ranging from 6 to 30. Also, the perceived reward of maladaptive behaviors (e.g., "It is easier to breathe without a mask.") was tested in seven items, with the scores ranging from 7 to 35 . Besides, the perceived response efficacy (e.g., "Recurrent washing of the hands with water and soap for at least 20 seconds can protect me against COVID-19.") was tested in seven items, with the scores ranging from 7 to 35 .

The perceived self-efficacy (e.g., "I can adequately and appropriately disinfect contaminated or suspected objects and areas.") was tested in six items, with the scores ranging from 6 to 30. Also, the perceived response cost (e.g., "Disinfecting contaminated objects and areas is time-consuming.") was tested in seven items, with the scores ranging from 7 to 35 . Besides, fear was tested in six items (e.g., "When I think about COVID-19, I feel anxious."), with the scores ranging from 6 to 30. Also, protection motivation (e.g., "I have decided not to travel until the disease is eradicated.") was tested in seven items, with the scores ranging from 7 to 35 . Finally, behavior (e.g. "I avoid kissing or shaking hands with others.") was tested in ten items, with the scores ranging from 0 to 40. The questionnaire also included Yes/No questions about the history of hypertension, diabetes, kidney disease, and cardiovascular diseases, and the participants were asked to answer these questions.

\section{Data analysis}

The frequency, percentage, mean, and standard deviation (SD) indices were measured to describe the data. To test the study hypotheses and explore the correlations of COVID-19 preventive behaviors with the demographic characteristics, t-test and one-way ANOVA test were used. Besides, to evaluate the correlations between the PMT constructs and preventive behaviors, a multivariate linear regression analysis was performed. Also, to investigate the interactions of the PMT constructs and accept or reject the conceptual theory for COVID-19 preventive behaviors, path analysis and structural equation modeling (SEM) were performed. All statistical analyses and hypothesis tests were carried out in SPSS Version 21 and AMOS Version 21, and the significance level was set at 0.05 .

\section{Results \\ Study sample}

In the present study, 2219 participants were included and completed the questionnaires online. Nonetheless, $3.9 \%(n=87)$ of the questionnaires were incomplete and discarded. Finally, 2032 questionnaires were analyzed in this study. The average age of the participants was $34.84 \pm 9.8$ years, ranging from 15 to 98 years. As the results showed, the mean score of protective behaviors was significantly higher among participants who were above 15 years, female, and married. Also, the mean scores of participants with a bachelor's degree or higher, healthcare staff, urban residents, non-smokers, and employed people were higher than others. The demographic information of the participants and the mean scores of protective behaviors are summarized in Table 1.

Table 2 presents the Cronbach's alpha coefficients and the range of scores for the PMT constructs. The crude mean scores, adjusted mean scores, percentages, and Pearson's correlation coefficients of the PMT constructs were measured in respect to the target protective behaviors. In the present study, significant positive correlations were found between the preventive behaviors of COVID-19 and the perceived vulnerability, perceived severity, response efficacy, self-efficacy, and protection motivation. On the other hand, significant negative correlations were found between the preventive behaviors of COVID-19 and maladaptive behavior rewards and perceived costs (Table 2).

Table 3 and Fig. 2 present the results of path analysis and SEM. Overall, the results of SEM showed that 35\% of variance in the dependent variable (COVID-19 preventive behaviors) could be explained by the independent variable (motivation) $\left(R^{2}=0.348\right)$. The $R^{2}$ for protection motivation was 0.330 , which indicates that $33 \%$ of variance in the dependent variable (motivation) could be explained by the independent variables (coping appraisal, fear, and threat appraisal). Moreover, coping appraisal, threat appraisal, and fear were significantly correlated with protection motivation $(P<0.001)$. Besides, motivation protection was significantly correlated with COVID-19 preventive behaviors $(P<0.001)$ (Table 3 and Fig. 2).

For the regression analysis of the PMT constructs, the backward regression method was applied. As shown in Table 4, maladaptive behavior rewards, response 
Table 1 The participants' demographic information

\begin{tabular}{|c|c|c|c|c|}
\hline Demographic information & Categories & $\begin{array}{l}\text { Frequency } \\
\mathrm{N}(\%)\end{array}$ & $\begin{array}{l}\text { Mean score of COVID-19 preventive behaviors } \\
\text { (SD) }\end{array}$ & $P$-value \\
\hline \multirow[t]{5}{*}{ Age (years) } & $15-20$ & $132(6.5)$ & $31.70(5.961)$ & $<.001$ \\
\hline & $21-30$ & $549(27)$ & $34.39(5.331)$ & \\
\hline & $31-40$ & $862(42.4)$ & $35.83(4.109)$ & \\
\hline & $41-50$ & $363(17.9)$ & $36(4.218)$ & \\
\hline & $>50$ & $126(6.2)$ & $36.44(3.928)$ & \\
\hline \multirow[t]{2}{*}{ Gender } & Male & $804(39.6)$ & $34.88(4.748)$ & .005 \\
\hline & Female & $1228(60.4)$ & $35.48(4.742)$ & \\
\hline \multirow[t]{3}{*}{ Marital status } & Single & $510(25.1)$ & $34.04(5.360)$ & $<.001$ \\
\hline & Married & $1464(72)$ & $35.64(4.367)$ & \\
\hline & Divorced/widow & $58(2.9)$ & & \\
\hline \multirow[t]{5}{*}{ Level of education } & Elementary school & $36(1.8)$ & $33.57(5.320)$ & $<.001$ \\
\hline & High school & $138(6.8)$ & & \\
\hline & Diploma & $442(21.8)$ & $34.21(5.394)$ & \\
\hline & Associate degree & $222(10.9)$ & $34.74(4.761)$ & \\
\hline & Bachelor's degree or higher & $1194(58.8)$ & $35.96(4.246)$ & \\
\hline \multirow[t]{6}{*}{ Occupation } & Student & $73(3.6)$ & $32.98(5.586)$ & $<.001$ \\
\hline & University student & $107(5.3)$ & & \\
\hline & Employee & $934(46)$ & $35.91(4.416)$ & \\
\hline & Self-employed & $252(12.4)$ & $34.31(5.219)$ & \\
\hline & Unemployed & $255(12.5)$ & & \\
\hline & Others & $411(20.2)$ & $35.87(3.943)$ & \\
\hline \multirow[t]{2}{*}{ Medical staff } & Yes & $354(17.4)$ & $36.21(4.704)$ & $<.001$ \\
\hline & No & $1678(82.6)$ & $35.04(4.739)$ & \\
\hline \multirow[t]{4}{*}{ Chronic diseases } & Hypertension & $154(7.6)$ & 36.06 (3.995) & 0.025 \\
\hline & Diabetes & $79(3.9)$ & $34.73(4.830)$ & 0.334 \\
\hline & Kidney disease & $101(5)$ & $34.46(4.916)$ & 0.089 \\
\hline & Cardiovascular disease & $71(3.5)$ & $35.30(4.083)$ & 0.921 \\
\hline \multirow[t]{2}{*}{ Smoking } & Yes & $217(10.7)$ & $34.24(4.781)$ & 0.001 \\
\hline & No & 1815 (89.3) & $35.36(4.736)$ & \\
\hline \multirow[t]{2}{*}{ Place of residence } & Urban & $1773(87.3)$ & $35.4(4.593)$ & $<.001$ \\
\hline & Rural & $259(12.7)$ & $34.16(5.617)$ & \\
\hline
\end{tabular}

efficiency, self-efficacy, and fear predicted the protective behaviors of COVID-19. According to the regression analysis, the PMT constructs could explain 39\% of variance in the protective behaviors of COVID-19. Among the PMT constructs, self-efficacy was the strongest predictor. Two variables, that is, reward and fear, were negatively correlated with the protective behaviors. In other words, higher scores of these two variables were associated with a lower score of COVID-19 preventive behaviors (Table 4).

The distribution (frequency and percentage) of protective behaviors, reported by the participants, is presented in Table 5 . The results showed that $79.8 \%$ of the participants always avoided unnecessary travel; $78.6 \%$ always avoided kissing or hand-shaking; and $74.4 \%$ wore masks if they approached a suspected person (Table 5).

\section{Discussion}

The present study aimed to predict the adoption of COVID-19 preventive behaviors, based on the PMT among Hormozgan residents, aged $\geq 15$ years. The results revealed that maladaptive behavior rewards, response efficacy, self-efficacy, and fear predicted the protective behaviors. Among the PMT constructs, self-efficacy was the strongest predictor. Also, the mean score of COVID19 preventive behaviors in the target population was above average, which can be due to awareness raising and management of the disease. 


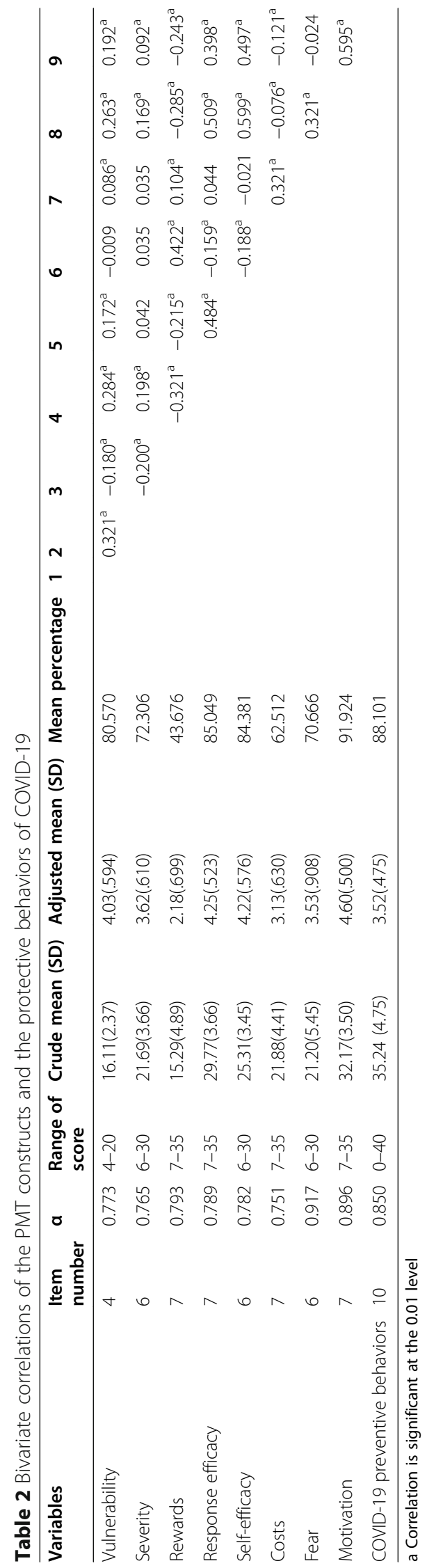


Table 3 The path analysis of the PMT model of COVID-19 preventive behaviors $(n=2032)$

\begin{tabular}{|c|c|c|c|c|}
\hline Dependent variable & Independent variables & Path confidence & t-statistic & $R^{2}$ \\
\hline COVID-19 preventive behaviors & Motivation & 0.590 & 32.907 & 0.348 \\
\hline \multirow[t]{3}{*}{ Motivation } & Coping appraisal & 0.518 & 28.538 & 0.330 \\
\hline & Threat appraisal & 0.142 & 7.792 & \\
\hline & Fear & 0.204 & 11.213 & \\
\hline
\end{tabular}

The present results showed a significant correlation between age and protective behaviors of COVID-19. In other words, older age was associated with a higher frequency of adopting protective behaviors, which could be attributed to the higher level of awareness and perceived threat at older age. Since older people are more prone to background diseases, they may be inclined to use protection more than others. Besides, the perceived severity, which is dependent on age, is higher among the elderly than the youth [37]. Moreover, in the present study, there was a significant association between preventive behaviors and education. In other words, individuals with a bachelor's degree or higher adopted more protective behaviors, which can be due to their higher level of knowledge. Therefore, based on the present results, it is necessary to design interventions to raise the awareness of less educated people in Hormozgan Province.

The present results also showed that women adopted more preventive behaviors than men. Several studies on other ethnicities have also confirmed differences between males and females regarding their health beliefs and healthy behaviors. These results showed that certain gender-specific plans need to be designed to reinforce the preventive behaviors of COVID-19. Besides, the results of Pearson's correlation coefficient test showed significant positive correlations between the preventive behaviors of COVID-19 and the perceived severity, vulnerability, response efficacy, self-efficacy, and protection motivation. On the other hand, significant negative correlations were found between the preventive behaviors of COVID-19 and the perceived rewards and costs; these findings are consistent with a number of previous studies $[28,38]$.

Considering the national and provincial restrictions for the management of COVID-19, which have led to limitations in many occupations, a large part of the community faces a significant economic burden. Therefore, it is necessary to pay attention to the possible adverse social and economic consequences of this disease, besides making attempts to control its spread [4, 39]. Moreover, economic vulnerability may result in people's reluctance to engage in protective behaviors. It seems that planning

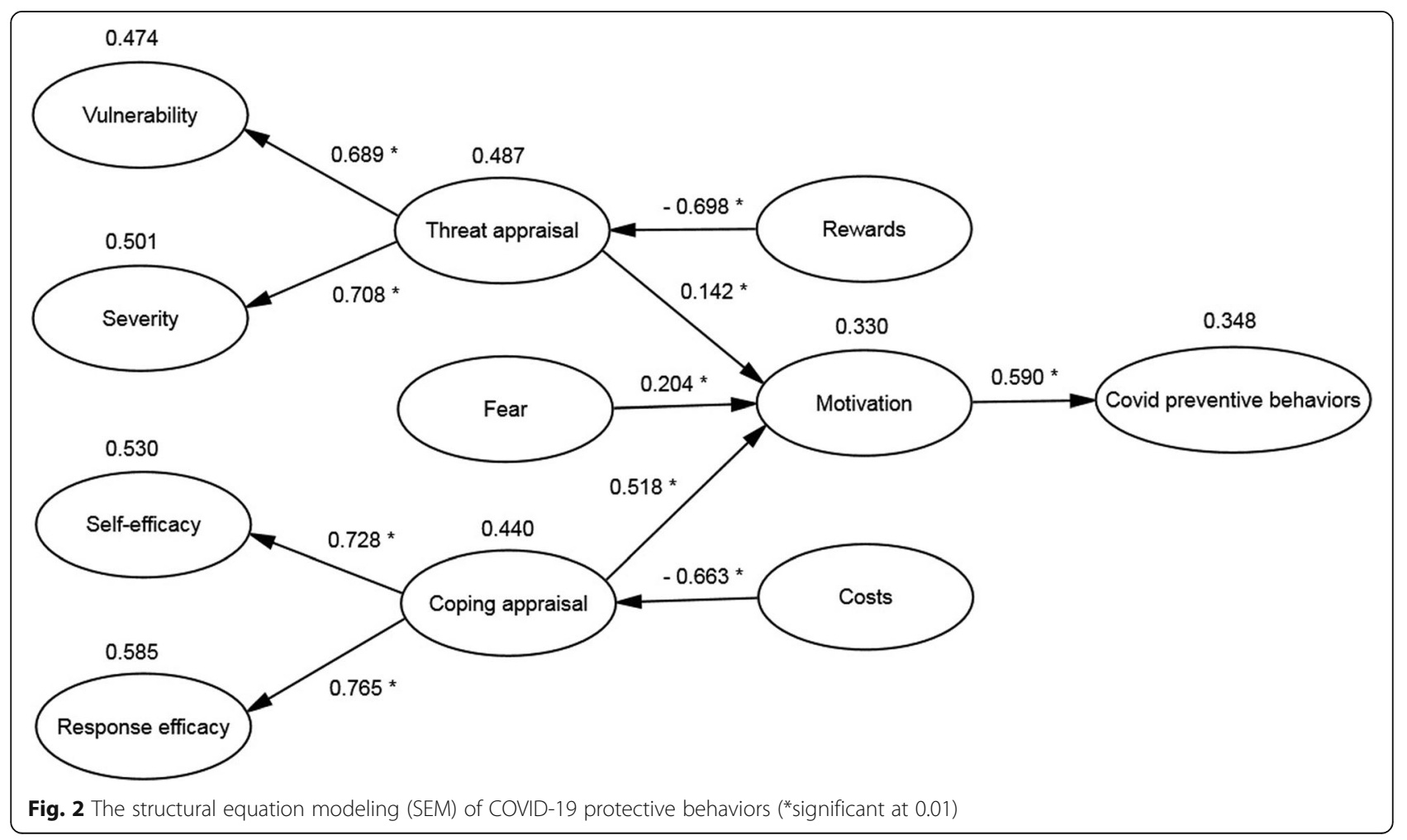


Table 4 Prediction of COVID-19 preventive behaviors according to the multiple regression analysis $(n=2032)$

\begin{tabular}{|c|c|c|c|c|c|c|c|c|}
\hline & \multicolumn{2}{|c|}{ Unstandardized coefficients } & \multirow{2}{*}{$\begin{array}{l}\text { Standardized coefficients } \\
\text { Beta }\end{array}$} & \multirow[t]{2}{*}{$\mathbf{t}$} & \multirow[t]{2}{*}{ Sig. } & \multicolumn{2}{|c|}{ 95\% Confidence interval for B } & \multirow[t]{2}{*}{$R^{2}$} \\
\hline & B & Std. error & & & & Lower bound & Upper bound & \\
\hline (Constant) & 8.764 & 1.024 & & 8.561 & $<.001$ & 6.757 & 10.772 & .398 \\
\hline Rewards & -.044 & .018 & -.046 & -2.454 & .014 & -.080 & -.009 & \\
\hline Response efficacy & .092 & .028 & .071 & 3.336 & .001 & .038 & .146 & \\
\hline Self-efficacy & .253 & .031 & .184 & 8.176 & $<.001$ & .192 & .313 & \\
\hline Fear & -.068 & .015 & -.078 & -4.404 & $<.001$ & -.098 & -.038 & \\
\hline
\end{tabular}

and management of local authorities to reduce the economic burden (e.g., providing appropriate facilities in local health centers) can be effective in encouraging people to show protective behaviors [39].

The present findings also revealed that COVID-19 preventive behaviors were significantly and positively correlated with the perceived vulnerability. In other words, if people perceive themselves as vulnerable to the disease, they adopt more protective behaviors; this finding is consistent with the results reported by Babazadeh et al. [32] and Mohammadi et al. [40]. Furthermore, the present results showed that protective behaviors and perceived severity were positively and significantly correlated. Therefore, if people are made aware of the health consequences of COVID-19, they will adopt more protective behaviors. This finding is in agreement with the results reported by Tazval et al. [41], but inconsistent with the results reported by Zare et al. [42].

In the present study, a significant positive correlation was observed between the perceived vulnerability and the severity of COVID-19. This finding is consistent with the results of studies by Barati et al. [43], Zare et al. [28], and Park et al. [44]. According to their results, for a better understanding of the risks of this disease, a higher level of perceived vulnerability is needed; therefore, perception can strongly and positively affect the perceived threat of COVID-19. Also, a significant positive correlation was found between the perceived response efficacy of preventive behaviors and the individual's self-efficacy and protection motivation. In other words, a greater understanding of the effectiveness of protective behaviors was followed by the increased level of self-efficacy, and vice versa. Moreover, a greater understanding of the effectiveness of protective behaviors was associated with higher motivation for protection, and vice versa; this finding is consistent with the study by Zare Sakhvidi et al. [28].

The present study also showed that COVID-19 preventive behaviors were significantly and positively correlated with protection motivation; however, this finding is inconsistent with the results reported by Kaviani et al. [45]. Based on the present results, the coping appraisal variables were the strongest predictors of protective behaviors in the target population. In line with several previous studies [28, 46], self-efficacy was the strongest predictor of these behaviors, followed by response efficacy. It seems that individuals with a higher level of selfefficacy perceive themselves to be capable of achievements; therefore, they show a tendency toward preventive behaviors of COVID-19.

Both response efficacy and self-efficacy are subsumed under coping appraisal in the PMT. The response

Table 5 Distribution of COVID-19 preventive behaviors in the participants

\begin{tabular}{llllllll}
\hline Preventive behaviors & $\begin{array}{l}\text { Never } \\
\mathbf{N}(\%)\end{array}$ & $\begin{array}{l}\text { Seldom } \\
\mathbf{N}(\%)\end{array}$ & $\begin{array}{l}\text { Sometimes } \\
\mathbf{N}(\%)\end{array}$ & $\begin{array}{l}\text { Mostly } \\
\mathbf{N}(\%)\end{array}$ & $\begin{array}{l}\text { Always } \\
\mathbf{N}(\%)\end{array}$ & Item mean & $\begin{array}{l}\text { Item SD } \\
\text { Going out of the house only in emergencies }\end{array}$ \\
\hline Avoiding kissing or shaking hands & $27(1.3)$ & $1(0)$ & $488(24)$ & $499(24.6)$ & $1017(50)$ & 3.22 & 0.902 \\
Avoiding touching the mouth, nose, and eyes & $24(1.2)$ & $0(0)$ & $75(3.7)$ & $355(16.5)$ & $1598(78.6)$ & 3.71 & 0.648 \\
Keeping a 1-2-m social distance & $10(.5)$ & $0(0)$ & $244(12)$ & $759(37.4)$ & $1019(50)$ & 3.37 & 0.729 \\
Using tissues while coughing/sneezing & $11(.5)$ & $2(.1)$ & $237(11.7)$ & $752(37)$ & $1030(50.7)$ & 3.37 & 0.734 \\
Avoiding crowded places & $8(.4)$ & $0(0)$ & $130(6.4)$ & $446(21.9)$ & $1448(71.3)$ & 3.64 & 0.638 \\
Washing hands regularly with water and soap for at least $20 \mathrm{~s}$ & $8(.4)$ & $1(.0)$ & $106(5.2)$ & $529(26)$ & $1388(68.3)$ & 3.62 & 0.625 \\
Avoiding unnecessary travel & $63(3.1)$ & $0(0)$ & $97(4.8)$ & $250(12.3)$ & $1622(79.8)$ & 3.66 & 0.833 \\
Stress management & $13(.6)$ & $0(.0)$ & $205(10.1)$ & $677(33.3)$ & $1137(56)$ & 3.44 & 0.725 \\
Wearing masks while approaching suspected cases of COVID-19 & $11(.5)$ & $0(.0)$ & $141(6.9)$ & $369(18.2)$ & $1511(74.4)$ & 3.66 & 0.655 \\
\hline
\end{tabular}


efficacy refers to the effectiveness of coping responses in reducing threats. Generally, self-efficacy involves the individual's perceived capability of showing a coping response. The regression coefficients showed that higher levels of self-efficacy and response efficacy could help increase motivation for preventing COVID-19. These findings are consistent with previous studies, which also adopted PMT as their theoretical framework.

The available coping strategies are effective in the adoption of protective behaviors. A high response efficacy strengthens self-protection and belief in the effectiveness of protective behaviors [47, 48]. The effect size of coping strategies or threats depends on the health issue to some extent. In the literature, the threat appraisal variables were the strongest predictors of cancer preventive behaviors. However, in terms of smoking, the coping appraisal variables were the strongest predictors of preventive behaviors [38]; the high educational level of the participants might be one of the contributing factors [49]. It should be noted that in the present study, the majority of the participants were in the age range of 31-40 years, which could be the main reason for the unprecedented effects of perceived severity and vulnerability in PMT on preventive behaviors. Overall, a higher self-efficacy can improve preventive behaviors in vulnerable populations $[50,51]$. Also, health promotion programs, with the aim of improving self-efficacy in COVID-19 preventive behaviors, may improve preventive behaviors and promote social health.

In the current study, maladaptive behavior reward and fear were negatively correlated with preventive behaviors. In other words, higher levels of fear and maladaptive behavior reward were related to the lower probability of adopting protective behaviors. It seems that awareness of maladaptive behavior rewards is more important than the perceived cost of healthy behaviors. According to previous studies on the global outbreak of COVID-19, the psychological consequences of home quarantine and social restrictions include fear, anxiety, and depression, which can have negative impacts on protective behaviors [5].

According to the literature, governments need to find effective ways to disseminate unbiased information about COVID-19, train appropriate preventive strategies, ensure the availability of essential services and goods, and provide adequate financial support to overcome this crisis $[1,52]$. Some other studies have reported similar findings regarding the use of condoms [53]. Conversely, in an investigation of cancer preventive behaviors in the workplace, the perceived costs were more important than the perceived rewards [28]. In the present study, protective behaviors were at a desirable level, which is consistent with a study by Barati et al. on COVID-19 protective behaviors in the hospital staff [37] and a study by Shahabi et al. on COVID-19 protective behaviors in Hormozgan Province [36]. Besides, a study by Wang et al. showed that the use of face masks during the COVID-19 pandemic could protect the physical and mental health of the public [6].

Since COVID-19 is a newly emerging disease, affecting many countries around the world, the information sources are being constantly updated. The adoption of acceptable protective behaviors is important during this pandemic. Overall, regular washing of the hands is the most important protective behavior, which was less adopted by the target population; therefore, awareness raising and education are of utmost importance. It is worth mentioning that behavioral change is generally a process that requires time. According to the theory adopted in this study, coping appraisal responses that lead to protection motivation are made after the threat appraisal process, because a threat needs to be identified before the appraisal of coping strategies. Therefore, attempts must be made as soon as possible to improve public awareness, create mutual trust, promote effective coping responses, and contribute to the achievement of plans.

\section{Strengths}

The present study is one of the very few studies applying health promotion models to explore the preventive behaviors of COVID-19. This research was conducted on a large sample size within the shortest time possible.

\section{Limitations}

The first limitation of this study is that online surveys can be only used by literate people, who have access to the Internet. Second, the majority of the participants in this study were young urban residents; therefore, the generalizability of the findings is limited. Third, physical health was reported by the participants themselves, and no acceptable evaluation tool was used. Fourth, people with mental illnesses were not included in this study, as they could not show proper preventive behaviors due to their psychological problems, such as stress and anxiety. Therefore, future studies are suggested to evaluate the performance of these individuals and propose appropriate plans.

\section{Conclusion}

The present findings revealed that the rewards of maladaptive behaviors and fear were the negative predictors of the protective behaviors of COVID-19. It is generally difficult to control this disease in Hormozgan Province, considering the cultural background of people in this region (e.g., visiting family and friends, hand shaking, and cheek kissing) and its hot weather that causes individuals to stay indoors and avoid wearing masks. Therefore, 
implementation of appropriate interventional programs is necessary, with attention to the rewards of maladaptive behaviors. Also, to manage fear in the community, appropriate planning is necessary by sending appropriate health messages and preventing the spread of fake news. Moreover, using appropriate psychological techniques and coping behaviors is recommended. In this study, the response efficacy and self-efficacy were the positive predictors of protective behaviors (self-efficacy was the strongest). It seems that proper planning for interventions to increase self-efficacy in the community can be a positive step toward the prevention and control of this disease. In this study, the participants' score of COVID19 preventive behaviors was above average, which could be due to appropriate awareness raising and management of the disease in the province. Among preventive behaviors, avoidance of unnecessary travel, avoidance of kissing/shaking hands, and wearing masks were the most common behaviors. Overall, the present findings can be applied for policymaking in target populations.

\section{Abbreviations}

PMT: Protection Motivation Theory; WHO: World Health Organization; SARS: Severe Acute Respiratory Syndrome; H1N1: Influenza Swine Flu; COVID19: Coronavirus Disease 2019; ANOVA: Analysis of Variance; SEM: Structural Equation Modeling

\section{Acknowledgements}

The authors express their gratitude to the Deputy of Research of Hormozgan University of Medical Sciences for funding this project.

\section{Authors' contributions}

TA contributed to the study design; SHM analyzed the data; RER wrote the manuscript and conducted data collection; NSH and MHA conceived the study, developed the study protocol and questionnaires, and supervised data collection; FN conducted data collection; and HKT designed the online questionnaire. All authors read and approved the manuscript.

\section{Funding}

This study received financial support from the Deputy of Research of Hormozgan University of Medical Sciences (grant No.: 980470). The study design, data collection, and data analysis were developed independently of the funder.

\section{Availability of data and materials}

The datasets used and/or analyzed during the study are available from the corresponding author on reasonable request.

\section{Declarations}

\section{Ethics approval and consent to participate}

This study was approved by the Ethics Committee of Hormozgan University of Medical Sciences (ethical code: IR.HUMS.REC.1398.479). The Ethics Committee approved the study to be conducted online and collect online consent. All participants, who provided an online consent form, were assured that their participation was voluntary and that they could leave the study at any time. Also, their data were anonymized, securely stored, and analyzed for publication. People under 16 years of age completed the questionnaires with written parental consent.

\section{Consent for publication}

Not applicable.

\section{Competing interests}

The authors declare that they have no competing interests.

\section{Author details}

Student Research Committee, Hormozgan University of Medical Sciences, Bandar Abbas, Iran. ${ }^{2}$ Social Determinants in Health Promotion Research Center, Hormozgan Health Institute, Hormozgan University of Medical Sciences, Bandar Abbas, Iran. ${ }^{3}$ Department of Community Medicine, School of Medicine, Hormozgan University of Medical Sciences, Bandar Abbas, Iran. ${ }^{4}$ Infectious and Tropical Diseases Research Center, Hormozgan Health Institute, Hormozgan University of Medical Sciences, Bandar Abbas, Iran. ${ }^{5}$ Cardiovascular Research Center, Hormozgan University of Medical Sciences, Bandar Abbas, Iran.

Received: 3 August 2020 Accepted: 24 February 2021

Published online: 08 March 2021

\section{References}

1. Tran BX, Dang AK, Thai PK, Le HT, Le XTT, Do TTT, et al. Coverage of health information by different sources in communities: implication for COVID-19 epidemic response. Int J Environ Res Public Health. 2020;17(10):3577.

2. Mahase E. China coronavirus: WHO declares international emergency as death toll exceeds 200. BMJ: British Medical Journal (Online). 2020;368.

3. WORLD HEALTH ORGANIZATION, et al. General's opening remarks at the media briefing on COVID-19. Gen. Open. remarks media Brief. COVID-19; 2020.

4. Burdorf A, Porru F, Rugulies R. The COVID-19 (coronavirus) pandemic: consequences for occupational health. Scand J Work Environ Health. 2020; 46(3):229-30.

5. Isralowitz R, Khamenka N, Konstantinov V, Gritsenko V, Reznik A. Fear, depression, substance misuse and related conditions among multi-national medical students at the peak of the COVID-19 epidemic. J Loss Trauma. 2020:1-4.

6. Wang C, Chudzicka-Czupała A, Grabowski D, Pan R, Adamus K, Wan X, et al. The association between physical and mental health and face mask use during the COVID-19 pandemic: a comparison of two countries with different views and practices. Front Psychiatry. 2020;11:901.

7. Chen S, Yang J, Yang W, Wang C, Bärnighausen T. COVID-19 control in China during mass population movements at new year. Lancet. 2020; 395(10226):764-6.

8. Khot WY, Nadkar MY. The 2019 novel coronavirus outbreak-a global threat. J Assoc Physicians India. 2020;68:67.

9. Abdi M. Coronavirus disease 2019 (COVID-19) outbreak in Iran: Actions and problems. Infect Control Hosp Epidemiol. 2020;41 (6):754-5.

10. Tan W, Hao F, Mclntyre RS, Jiang L, Jiang X, Zhang L, et al. Is returning to work during the COVID-19 pandemic stressful? A study on immediate mental health status and psychoneuroimmunity prevention measures of Chinese workforce. Brain Behav Immun. 2020;87:84-92.

11. Javidan M, Dastmalchian A. Managerial implications of the GLOBE project: a study of 62 societies. Asia Pac J Hum Resour. 2009;47(1):41-58.

12. Guan Y, Deng H, Zhou X. Understanding the impact of the COVID-19 pandemic on career development: insights from cultural psychology. J Vocat Behav. 2020;119:103438.

13. Aghamolaei T, Davoodi SH, Moradabadi AS, Dadipoor S. Association between social capital and quality of life in the Iranian population: a systematic review. J Sabzevar Univ Med Sci. 2020;26(6):695-707.

14. Kang JHY, Mason RN, Tarshis TP. 51.14 Relationship between religion/ spirituality and mental health in youth during COVID-19. J Am Acad Child Adolesc Psychiatry. 2020;59(10):S255.

15. Kowalczyk O, Roszkowski K, Montane X, Pawliszak W, Tylkowski B, Bajek A. Religion and faith perception in a pandemic of COVID-19. J Relig Health. 2020;59(6):2671-7.

16. Wu Z, McGoogan JM. Characteristics of and important lessons from the coronavirus disease 2019 (COVID-19) outbreak in China: summary of a report of 72314 cases from the Chinese Center for Disease Control and Prevention. JAMA. 2020;323(13):1239-42.

17. Sommestad T, Karlzén $\mathrm{H}$, Hallberg J. A meta-analysis of studies on protection motivation theory and information security behaviour. Int J Inf Secur Privacy. 2015;9(1):26-46.

18. Rogers RW. A protection motivation theory of fear appeals and attitude change1. J Psychol. 1975;91(1):93-114.

19. Sadeghi R, Mazloomy Mahmoodabad SS, Fallahzadeh H, Rezaeian M, Bidaki R, Khanjani N. Predictive factors for preventing hookah smoking and health 
promotion among young people based on the protection motivation theory. J Educ Health Promot. 2019;8:169.

20. Taheri-Kharameh Z, Bashirian S, Heidarimoghadam R, Poorolajal J, Barati M, Rásky É. Predictors of fall protective behaviors among Iranian communitydwelling older adults: an application of the protection motivation theory. Clin Interv Aging. 2020;15:123.

21. Bao Y, Sun Y, Meng S, Shi J, Lu L. 2019-nCoV epidemic: address mental health care to empower society. Lancet. 2020;395(10224):e37-e8.

22. Yehudai M, Bender S, Gritsenko V, Konstantinov V, Reznik A, Isralowitz R. COVID-19 fear, mental health, and substance misuse conditions among university social work students in Israel and Russia. Int J Ment Health Addiction. 2020;1-8

23. Morovati SMA, Rouhani TN. Social support and self-care behaviors in diabetic patients referring to Yazd Diabetes Research Center; 2008.

24. Sharifirad G, Yarmohammadi P, Sharifabad MA, Rahaei Z. Determination of preventive behaviors for pandemic influenza A/H1N1 based on protection motivation theory among female high school students in Isfahan, Iran. J Educ Health Promot. 2014;3:7.

25. Sadique MZ, Edmunds WJ, Smith RD, Meerding WJ, De Zwart O, Brug J, et al. Precautionary behavior in response to perceived threat of pandemic influenza. Emerg Infect Dis. 2007;13(9):1307.

26. Watkins RE, Cooke FC, Donovan RJ, Macintyre CR, Itzwerth R, Plant AJ. Influenza pandemic preparedness: motivation for protection among small and medium businesses in Australia. BMC Public Health. 2007;7(1):157.

27. Ling M, Kothe EJ, Mullan BA. Predicting intention to receive a seasona influenza vaccination using protection motivation theory. Soc Sci Med. 2019:233:87-92.

28. Zare Sakhvidi MJ, Zare M, Mostaghaci M, Mehrparvar AH, Morowatisharifabad MA, Naghshineh E. Psychosocial predictors for Cancer prevention behaviors in workplace using protection motivation theory. Adv Prev Med. 2015;2015:467498.

29. Lowe JB, Borland R, Stanton WR, Baade P, White V, Balanda K. Sun-safe behaviour among secondary school students in Australia. Health Educ Res. 2000;15(3):271-81.

30. Jiang X, Elam G, Yuen C, Voeten H, de Zwart O, Veldhuijzen I, et al. The perceived threat of SARS and its impact on precautionary actions and adverse consequences: a qualitative study among Chinese communities in the United Kingdom and the Netherlands. Int J Behav Med. 2009;16(1):58-67.

31. Valigosky MA. Infection control perceptions and practices of spiritual care providers: an application of the protection motivation theory. The University of Toledo; 2009.

32. Babazadeh T, Nadrian H, Banayejeddi M, Rezapour B. Determinants of skin Cancer preventive behaviors among rural farmers in Iran: an application of protection motivation theory. J Cancer Educ. 2017;32(3):604-12.

33. Moeini B, Ezati E, Barati M, Rezapur-Shahkolai F, Mohammad Gholi Mezerji N, Afshari M. skin Cancer preventive behaviors in Iranian farmers: applying protection motivation theory. Workplace Health Saf. 2019;67(5):231-40

34. Kuchaksaraei BS, Danehkar A, Fatemi SM, Jozi SA, Ramezani-Fard E. An investigation on the human impact intensity on the selected ecoregions of coastal areas of Hormozgan Province, Persian Gulf, Strait of Hormuz, South of Iran. Environment, Development and Sustainability. 2020;1-7.

35. Ghaedi S. Evaluation and zoning of wind power in Hormozgan Province, Iran. Environ Energy Econ Res. 2017;1(4):373-82.

36. Shahabi N, Takhti HK, Azad MH, Rad RE, Ghaffari HR, Mohseni S, Aghamolaei T, Norozian F. Knowledge, attitude, and preventive behaviors of Hormozgan residents toward COVID-19, one month after the epidemic in Iran. J Public Health. 2021;1-2.

37. Bränström R, Chang Y-M, Kasparian N, Affleck P, Tibben A, Aspinwall LG, et al. Melanoma risk factors, perceived threat and intentional tanning: an online survey. Eur J Cancer Prev. 2010;19(3):216.

38. Floyd DL, Prentice-Dunn S, Rogers RW. A meta-analysis of research on protection motivation theory. J Appl Soc Psychol. 2000;30(2):407-29.

39. Tran BX, Vu GT, Latkin CA, Pham HQ, Phan HT, Le HT, et al. Characterize health and economic vulnerabilities of workers to control the emergence of COVID-19 in an industrial zone in Vietnam. Saf Sci. 2020;129:104811.

40. Mohammadi S, Baghiani Moghadam MH, Noorbala MT, Mazloomi SS, Fallahzadeh H, Daya A. Survey about the role of appearance concern with skin cancer prevention behavior based on protection motivation theory. J Dermatol Cosmet. 2010;1(2):70-7.

41. Tazval J, Ghafari M, Mohtashami Yeganeh F, Babazadeh T, Rabati R. Efficiency of protection motivation theory on prediction of skin cancer and sunlight preventive behaviors in farmers in Ilam county. J Health. 2016;7(7): 656-67.

42. Zare M, Fallahzadeh $\mathrm{H}$. Study of determinants of lung cancer protective behaviors in Esfahan steel company workers based on protection motivation theory. Tolooebehdasht. 2017;16(3):67-80.

43. Barati M, Bashirian S, Jenabi E, Khazaei S, Karimi-Shahanjarini A, Zareian S, et al. Factors Associated with Preventive Behaviours of COVID-19 among Hospital Staff in Iran in 2020: An application of the protection motivation theory. J Hosp Infect. 2020, 105(3):430-3.

44. Park JH, Cheong HK, Son DY, Kim SU, Ha CM. Perceptions and behaviors related to hand hygiene for the prevention of H1N1 influenza transmission among Korean university students during the peak pandemic period. BMC Infect Dis. 2010;10:222.

45. Khorsandi M. The assessment of the protection motivation theory construct of skin cancer preventive behaviors in rural women. Sci J Hamadan Nurs Midwifery Fac. 2016;24(4):229-37.

46. Leigh L, Taylor C, Glassman T, Thompson A, Sheu J-J. A cross-sectional examination on the factors related to emergency nurses' motivation to protect themselves against an ebola infection. J of Emerg Nurs. 2020;46(6): 814-26.

47. Rippetoe PA, Rogers RW. Effects of components of protection-motivation theory on adaptive and maladaptive coping with a health threat. J Pers Soc Psychol. 1987;52(3):596.

48. Milne $S$, Sheeran P, Orbell S. Prediction and intervention in health-related behavior: a meta-analytic review of protection motivation theory. J Appl Soc Psychol. 2000;30(1):106-43

49. Gu C, Chan CW, Twinn S, Choi KC. The influence of knowledge and perception of the risk of cervical cancer on screening behavior in mainland Chinese women. Psychooncology. 2012;21(12):1299-308.

50. Sarkar U, Fisher L, Schillinger D. Is self-efficacy associated with diabetes selfmanagement across race/ethnicity and health literacy? Diabetes Care. 2006; 29(4):823-9.

51. Grembowski D, Patrick D, Diehr P, Durham M, Beresford S, Kay E, et al. Selfefficacy and health behavior among older adults. J Health Soc Behav. 1993; 34(2):89-104.

52. Wang C, Pan R, Wan X, Tan Y, Xu L, RS Ml, et al. A longitudinal study on the mental health of general population during the COVID-19 epidemic in China. Brain Behav Immun. 2020;87:40-8.

53. Parsons JT, Halkitis PN, Bimbi D, Borkowski T. Perceptions of the benefits and costs associated with condom use and unprotected sex among late adolescent college students. J Adolesc. 2000;23(4):377-91.

\section{Publisher's Note}

Springer Nature remains neutral with regard to jurisdictional claims in published maps and institutional affiliations.

Ready to submit your research? Choose BMC and benefit from:

- fast, convenient online submission

- thorough peer review by experienced researchers in your field

- rapid publication on acceptance

- support for research data, including large and complex data types

- gold Open Access which fosters wider collaboration and increased citations

- maximum visibility for your research: over $100 \mathrm{M}$ website views per year

At BMC, research is always in progress.

Learn more biomedcentral.com/submissions 